\title{
The psychological safety of the educational environment and the psychological well-being of Russian secondary school pupils and teachers
}

\author{
Irina A. Baeva ${ }^{\mathrm{a}}$, Nina V. Bordovskaia ${ }^{\mathrm{b} *}$ \\ ${ }^{a}$ Herzen State Pedagogical University of Russia, St. Petersburg, Russia \\ ${ }^{b}$ St. Petersburg State University, St. Petersburg, Russia \\ *Corresponding author. E-mail: nina52@mail.ru
}

The interest of psychologists in the study of safety in the educational environment and its psychological characteristics is increasing. The aim of this study was to select, substantiate, and disclose the psychological factors in the educational environment that influence the psychological well-being of pupils. There were three stages in our research: clarifying the level of psychological safety in the schools in the study; revealing the consistency of the teachers' and the students' evaluations of the level of psychological safety in those schools; determining the nature of the influence of the psychological safety of the educational environment on the psychological well-being of the students. The study involved 172 teachers and 876 students in Moscow and St. Petersburg schools.

Psychological safety is a condition of educational environments that are free from psychological violence in the interactions of the people in them; psychological safety contributes to the satisfaction of the needs for personal trust and communication, creates for the participants a sense of belonging (the referential importance of the environment), and contributes to their mental health.

The empirical study revealed that (1) the level of the psychological safety of the educational environment in the evaluations of the teachers was higher and had more expressed differentiation than did the level in the students' evaluations; (2) the psychological well-being of the students was closely correlated with the level of psychological safety for the teachers; (3) such components of the well-being of the students as emotional comfort, self-confidence, a higher level of cognitive activity were developed in those schools with high levels of psychological safety for the teachers.

The results can be useful in educational psychology and environmental psychology as well as when creating technologies to support the safety of school environments and of the people in them, including situations related to minimizing safety violations and reducing risks and threats.

Keywords: educational environment, psychological safety, psychological well-being of pupils 


\section{Introduction}

The interest of psychologists in the study of the educational environment and its psychological resources is increasing because, with the active development of continuous education in Russia and other countries, the number of people in this environment at different stages of life (not only in childhood and the traditional school years) is increasing. The educational environment occupies a special place because of the importance of its influence on personal development. Vygotsky (1982, p. 127) wrote, "The impact of the environment on child development will be measured among other influences as well as the degree of understanding, awareness, and comprehension of what is happening in the environment." Vygotsky was one of the first Russian psychologists who turned to the study of the sociohistorical determination of the psyche.

With the end of the twentieth century, Russian psychologists have shown considerable interest in the psychological problems of ecology and the development of children's minds in the process of interaction with the environment. As a result, several productive approaches to determining the psychological sense of the educational environment and its role in personality development and socialization have appeared (Rubtsov, 2009; Slobodchikov, 2000).

First, a significant claim of this research was the idea that the educational environment influences human behavior: its objective properties preset the universal "framework" in which individual development and behavior take place (Panov, 2007).

Second, there were new approaches to the study of the influence of the educational environment on a pupil's personality and its development (Baeva, Volkova, \& Laktionova, 2011) and on the professional and personal development of the student (Bordovskaia, 2012).

Third, psychological studies have proven that people can develop only in an environment with certain parameters, one of the most significant of which is safety (Baeva, 2002). Safety is a basic human need, and it has a key role in providing for the mental health and development of children.

Thus, the study of the psychological safety of the educational environment as a psychopedagogical reality and set of conditions that provide for the positive development and the formation of the personality of each participant in the educational process is extremely relevant in view of the ongoing acts of violence against children, groups, or communities in the context of the family, kindergarten, or school. Violence is the main source of psychotrauma, a factor in the deterioration of mental health (Volkova, 2011).

The search for tools of psychological resistance and the conditions that reduce threats and mitigate the risk of safety inhibition is not only a social need in modern conditions but also the task of special studies. In the psychological context the search for tools and conditions for studying the perception, cognition, and assessment of the educational environment for the development of students and teachers is beginning.

The modern system of Russian education is in the process of being reformed and is offering fundamentally different activities to teachers and students; these changes raise the necessity for the stability of these participants in the educational environment and their ability to overcome difficulties. The basic goal is the preservation of graduates' health - physical, mental, and psychological. The psychologi- 
cal aspects of achieving this goal lie within the framework of providing support for the psychological well-being of teachers and students.

Many psychologists are guided by the model developed by C. D. Ryff (Ryff \& Singer, 2008) for understanding and studying psychological well-being. This model proposes these structural components of psychological well-being: a positive attitude toward oneself and one's past life, relationships with people that are imbued with care and confidence, the ability to follow one's own beliefs, the ability to meet the requirements of everyday life (competence), goals and activities that give meaning to life, and continued development and self-realization. The theoretical foundations of each of these components can be found in the following theories and concepts: the theory of self-actualization of A. Maslow, the theory of personality development of E. Erickson, the theory of individuality of K. Jung, and the theory of desire for meaning of V. Frankl and others.

According to Diener and Diener (1996), psychological well-being includes cognitive assessment of different aspects of life, emotional self-acceptance, and the experience of subjective well-being comparable to the experience of happiness. Psychological well-being is determined not so much by the circumstances of life as by stable personality characteristics. In a study by Shek (2007) psychological well-being was revealed through components such as hopelessness/hopefulness, abilities, life satisfaction, and self-respect.

Thus, the applied aspects of psychological well-being are well represented in foreign research, while Russian research has considered psychological well-being only within the framework of activity theory and personality development. These differences highlight the contradiction between understanding the complex of psychological factors and conditions ensuring the safety of the Russian school and the need for practical psychologists and educational practice to account for the main psychological factors that determined the problem field and the purpose of this study.

The problem of this study is to find answers to the following questions:

- How can we understand and determine the psychological characteristics of the educational environment in regard to its safety for the mental development of teacher and student?

- Are there any differences between teachers' and students' estimates of the psychological safety of a school's environment?

- Which psychological conditions of the educational environment provide for the psychological well-being of pupils in secondary school?

The aim of the study was the selection, substantiation, and disclosure of the psychological factors of the educational environment that influence the psychological well-being of pupils in the Russian sociocultural and educational megacities, Moscow and St. Petersburg.

\section{The theoretical basis of the empirical research}

The theoretical premise of the study is that there is a connection between the level of psychological safety of an educational environment and the psychological wellbeing of its participants. It is therefore important to determine the psychological 
safety of an educational environment and the characteristics that help determine the level of safety for all its participants.

This premise and our previous studies (Baeva, 2002; Baeva et al., 2011; Bordovskaia, 2013) allow us to formulate a basic definition of the educational environment and to clarify its psychological characteristics. The educational environment is the psychological-pedagogical reality that contains specially arranged social and spatial-thematic conditions for personality formation and development opportunities. From our point of view, the psychological essence of an educational environment can be disclosed or determined through (a) the personal characteristics of the participants; (b) the features of their interactions; (c) the content of the education provided and the means of its transmission. On the basis of this understanding, the psychological quality of the educational environment manifests itself in the evolving relationship between teachers and students.

We complete our understanding of the educational environment with a characterization of the conditions that ensure the positive personality development of each participant. As Maslow (1954, p. 194) writes:

[For] fostering self-actualization or health, a good environment (in theory) is one that offers all necessary raw materials and then gets out of the way and stands aside to let the (average) organism itself litter its wishes and demands and make its choices (always remembering that it often chooses delay, renunciation in favor of others, etc., and that other people also have demands and wishes).

Psychologists use different characteristics to describe a «good» educational environment - for example, the developmental character of the environment, its provision of psychological comfort. We suggest considering psychological safety as one of these important psychological characteristics.

Safety is the feeling of protection (human and environmental) as well as the ability to reject negative external and internal threats (Baeva, 2002). The need for safety is a basic human need, but in the psychological context it has an enhanced role in determining the prospects for positive development in the presence or absence of traumatic deformation of the personality structure. At certain stages of ontogenesis (early childhood), disregard for this need leads to a threat to life or to uncompensated mental health consequences. Therefore, an important aspect in choosing tools for providing safety is an understanding of psychological safety in the educational environment and the role of psychological factors, which in our analysis of the educational environment we considered mostly from the point of view of safety for students.

Psychological safety occurs in an educational environment when it is free from psychological violence in the interactions of its participants; psychological safety contributes to satisfaction of the needs for personal trust and communication, creates the referential importance of the environment (gives one a sense of belonging), and promotes mental health. The nature of social interaction in the educational environment creates the reference environment, the psychological safety of its members, and their satisfaction with the components of their interpersonal interactions.

On the basis of this approach we can develop the concept of the psychological safety of the educational environment as the protection of participants from threats 
to positive development and mental health in the process of the pedagogical interaction. We have proposed the following provisions as conceptual ideas for psychological safety (Baeva, 2002; Baeva et al., 2011; Bordovskaia, 2012):

1. An important condition for the developmental character of an educational environment is its psychological safety.

2. Teachers should use methods and technologies that present a minimal risk of harming the formation and development of students' personalities in order to ensure their stability and resistance to negative influences.

3. The main threat to the psychological safety of participants in the educational environment is psychotrauma in the communication process, which can damage positive development and mental health and can be an obstacle to self-actualization.

4. The main source of psychotrauma in participants in the educational environment is psychological violence in pedagogical and interpersonal interactions.

5. Pedagogical and interpersonal interactions in the educational environment are psychologically safe if they promote a sense of belonging, convince participants that they are out of danger (the absence of the above-named threats), and strengthen mental health.

6. Providing psychological safety in an educational environment and, as a consequence, protection and support of the mental health of its participants should be a priority for practical psychology in education.

We assume that the most important outcome of children's presence in an educational environment with a high level of psychological safety is their psychological well-being, a necessary condition for personal development and the preservation of mental health.

In Russian studies psychological well-being is reviewed through selection of the components of a person's well-being: social, spiritual, material, physical, psychological (Kulikov, 2004). Psychological well-being is characterized by coordination of mental processes and functions, a sense of integrity, and inner balance. All these components are closely interrelated and influence each other. Well-being depends on clear goals, the successful implementation of plans for activities and behavior, the availability of resources, and the necessary conditions for achieving the goals. Trouble occurs as a result of frustration, the presence of negative factors in the social environment (violence, threats), and other similar conditions.

In our study, psychological well-being is a structure that includes the features of the mental state and personality that are relevant to a person's ability to successfully overcome obstacles in relationships with other people. At the same time, we note the importance of the positive experience of overcoming difficult situations in the development of psychological well-being, so let us consider this as a quality of personality. From our point of view, the experience of well-being/ill-being determines a person's focus on achieving a certain level in the system of social relationships and determines the social position of the person in the environment. Theoretical analysis has allowed us to confirm that the psychological safety of the educational environment has as its qualitative characteristic the condition of supporting the 
psychological well-being of adolescents. A lack of psychological safety in the case of intense psychological violence in the educational environment can reduce the well-being of adolescents and result in a low level of emotional comfort and selfconfidence.

The rapid increase in the quantity and diversity of risk in the educational environment has intensified the attention of researchers on the problem of the psychological well-being of adolescents in the modern metropolis, and, in particular, the problem of the well-being of adolescents in the school environment.

On the basis of this analysis, the hypotheses of the study were formulated:

1. There are differences between pupils' and teachers' evaluations of psychological safety in the school environment.

2. The level of the psychological safety of the educational environment for teachers affects the psychological well-being of students.

\section{Method}

\section{Research design}

There were three stages in our research. In the first stage we clarified the understanding of the psychological safety of the educational environment and selected the methods and the indicators for identifying the level of psychological safety in the schools we studied. In the second stage the strategy and design were determined; methods for obtaining the teachers' and the students' evaluations of the level of psychological safety in their educational environment as well as for determining the extent of the consistency of their evaluations were selected. In the third stage the nature of the influence of the psychological safety of the educational environment for the teachers on the psychological well-being of the students was determined.

The study involved 172 teachers and 876 young adolescents (13-14 years) and older adolescents (15-17 years) in 12 Russian schools in Moscow and St. Petersburg. A pilot comparative study did not reveal significant differences in the parameters for assessing the status of the schools' educational environment in the two cities. In addition, we analyzed the obtained empirical results in a single sample.

\section{Methods}

The method of the "psychological safety of the educational environment of the school" of I. A. Baeva (2002) was used to identify the level of the psychological safety of the educational environment and the calculation of the index of psychological safety of the educational environment in the evaluations of the teachers and the students. The method consists of questionnaires in versions for teachers and for students-adolescents; each version includes 11 questions with the proposed scales of responses containing the scores for characteristics of the educational environment.

In accordance with the theoretical concept of the psychological safety of the educational environment three integral indicators of safety as measured by this method were found. The first indicator was the significance (referentiality) of the educational environment for the teachers and the students. The empirical criterion was attitude to the educational environment - positive, neutral, or negative - as 
measured by a scale system containing cognitive, emotional, and behavioral components of this attitude. The second indicator was the teachers' and the students' satisfaction with basic features of their interactions. The empirical criterion was school-environment satisfaction, calculated as the total score of the characteristics of a school's social environment that were included in this method. Analysis of the category of mental violence in interpersonal interactions allowed us to accept the level of protection against mental violence as the third indicator of psychological safety in the educational environment. The index of the psychological safety of the educational environment was determined by totaling the estimates for the three indicators: protection against mental violence in interpersonal interactions; the significance of the environment; satisfaction with the basic sociopsychological characteristics of the environment.

In addition to the basic components of the psychological safety of the educational environment, the method allowed us to detect the levels of the cognitive, emotional, and behavioral significance of this environment for its participants. Thus, by assessing the protection of participants in the educational environment against mental violence in addition to analyzing their protection against various manifestations of mental violence - such as public humiliation, insults, threats, enforcement, withdrawal of attention - and hostile attitude, we could identify the sources of this protection. In particular, for the students the sources could be peers and teachers, and for the teachers the sources could be colleagues and students. The method allowed us to analyze satisfaction with characteristics of the educational environment - relationships with teachers and students, the opportunity to express one's point of view, respect for oneself, the preservation of personal dignity, and the ability to summon aid, to be proactive, and to take into consideration personal problems and difficulties. Having two types of participants in the study the students and the teachers - helped us to determine the level of psychological safety of a school's environment and to conduct a comparative analysis on the basis of their evaluations.

To identify the components of the psychological well-being of the students we used the Scale of Subjective Well-Being, a technique for diagnosing personal creativity by E. E. Tunik (2002), and the Life Orientation Test as adapted by D. A. Leontiev (2000). The developers of the Scale of Subjective Well-Being were French psychologists A. Perrudent-Badox, G.A. Mendelsohn, and J. Chiche, who published it in 1988. In studying the impact of individual health on emotional well-being, researchers were faced with the need to develop a method for individuals to assess their own emotional state. In Russia the technique was adapted by M. C. Sokolova (1996). The scale consists of 17 items aimed at measuring the emotional components of psychological well-being and identifying the level of emotional comfort. Participants rate the level of their agreement with the proposed statements on a 7-point scale. The evaluation allows determination of the level of well-being, the characterization of such parameters as intensity and sensitivity, the identification of the characteristics that accompany the main psychoemotional symptoms and mood changes, and the importance of the social environment, self-esteem, health, and satisfaction with daily activities.

The technique for diagnosing creativity helps to identify the level of individual creativity based on the evaluation of its components, such as curiosity, imagination, 
complexity, and risk-proneness. The scale Curiosity characterizes the interest of adolescents in the events and phenomena of the world around them and their desire to learn new things and to find new ways of solving problems. The scale Imagination describes adolescents' ability to fantasize. The scale Complexity characterizes the desire to formulate and solve complex problems and the persistence displayed in doing so. The scale Risk-proneness is not without interest in the context of our study because it allowed us to estimate teenagers' persistence in asserting ideas contrary to those of other people and to identify whether they resist alien influences, admit the possibility of their making mistakes, and perceive a difficult situation as a challenge and a test.

The Life Orientation Test is an adapted version of the Purpose in Life test of James Crambo and Leonard Maholik. The test reveals the presence of time perspective and the meaning of life (the scale Purpose in Life); the view of life as interesting and emotionally intense (the scale Life Process); satisfaction with life (the scale Outcomes of Life); one's self-image as a person with freedom of choice throughout life (the scale Locus of Self-Control); one's self-image as a person capable of controlling life (the scale Locus of Life Control).

For statistical data processing we used descriptive analysis, chi-square criteria, and Spearman correlation analysis to evaluate the study objectives.

The proof of the assumption that the level of the psychological safety of the educational environment for teachers can influence the psychological well-being of students was carried out using a one-way ANOVA test.

\section{Results}

\section{Teacher's and students' evaluations of the psychological safety level of the educational environment}

The data showed the heterogeneity of the level of the psychological safety of the educational environment in the schools studied in Moscow and St. Petersburg. This fact confirms the validity of the developed method for evaluating the psychological safety of the educational environment. Empirical measures of the safety level of the school environment allowed us to rank educational institutions on this indicator.

In analyzing the results, we found that in addition to schools with high and low levels of psychological security some schools had differences in the levels of psychological security in the evaluations of the teachers and the students. The existence of an educational environment with a high level of psychological safety for one group of participants and a low for another group raises some questions, the most topical being: (1) What is the reason for participants' differing perceptions of the levels of psychological safety in the same environment? (2) Are these differing assessments due to the fact that the psychological safety of teachers and students is determined by various factors?

To answer these questions a subsample was composed of the 5 schools in which estimates of the level of psychological safety by the teachers and the students had significant differences. The sample consisted of 305 people, 181 adolescent students and 124 teachers. The results are shown in Figure 1. 


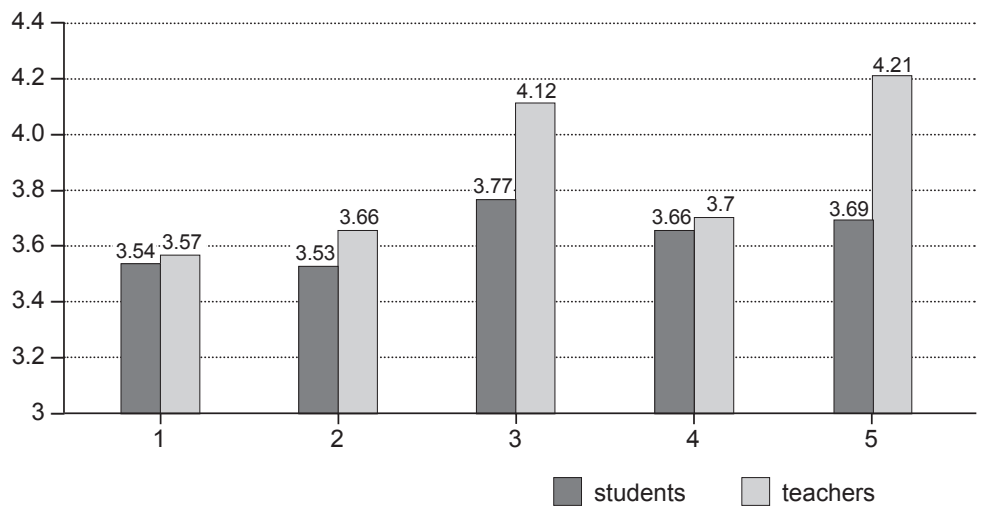

Figure 1. The level of psychological safety of the educational environment in the evaluations of teachers and students

(horizontal axis: the 5 schools participating in the study; vertical axis: the level of psychological safety in the educational environment (scale of 1 to 5 , where 1 indicates a low level of safety and 5 indicates a high level of safety).

Comparative analysis of the results showed that, first, the level of the schools' psychological safety in the estimates of both groups of participants was the same. In other words, if we rank the educational institutions in order of the decreasing index of psychological safety of the educational environment resulting from the surveys of the teachers and the students separately, we get no large variations of this index.

Second, in all the schools the level of the psychological safety of the educational environment was higher in the estimates of the teachers than of the students. This result can be explained by considering the age and status-role characteristics of the participants. The educational environment for the teachers was the main place of their professional life, so its axiological content was more significant for them than for the students. Hence, the teachers were more sensitive than the students during the assessment of its psychological safety.

Third, differences in the level of the psychological safety of the educational environment in different schools were expressed more in the evaluations of the teachers than of the students. Differences in the students' evaluations of the level of psychological safety were insignificant. This result not only may strengthen the assumption about the greater axiological richness of the educational environment for teachers but also may indicate that the psychological safety of the educational environment for the teachers and the students can be determined by various factors. In addition, the result was influenced by the teachers' understanding that the psychological safety of the educational environment is a prerequisite for its safety, especially for students.

\section{The influence of the psychological safety of the educational environment for teachers on students' psychological well-being}

Theoretical and empirical analyses of the psychological safety of the educational environment have shown that this parameter is an important characteristic of conditions that enhance the learning process. The psychological safety of the educational 
environment affects the mental development of the individual. In this study we verified this assumption: the psychological safety of the teachers influenced the psychological well-being of the students. For this analysis we used one-way ANOVA.

We established that the level of the development of the components of the students' psychological well-being changed depending on the level of the psychological safety of the educational environment for the teachers. In particular, our study revealed the influence of the psychological safety of the educational environment for teachers on these components of emotional well-being: intensity and sensitivity $(F=2.48 ; p \leq .05)$, importance of the social environment $(F=3.76 ; p \leq .01)$, selfscoring of health $(F=6.42 ; p \leq .001)$; life orientation - perception of life as interesting and emotionally intense $(F=4.63 ; p \leq .001)$, considering oneself a person with freedom of choice in life $(F=2.88 ; p \leq .05)$, considering oneself a person capable of controlling one's life $(F=2.84 ; p \leq .05)$; parts of personal creativity - risk-proneness $(F=4.42 ; p \leq .001)$, curiosity $(F=6.11 ; p \leq .001)$, desire to formulate and solve complex problems and persistence in doing so $(F=3.30 ; p \leq .01)$.

The results showed that, in the educational environments with a high level as opposed to a low level of psychological security for the teachers, the students had a more stable emotional state: positive emotions and feelings, a great interest in the social environment, self-confidence, and the ability to change a situation. In these educational environments the students had more cognitive activity and more persistence when performing educational tasks than students in educational environments with a low level of psychological security.

Thus, the empirical study had the following results:

(1) The level of psychological safety of the educational environment varied considerably in the educational institutions studied.

(2) There were differences in the teachers' and the students' evaluations of the psychological safety of the environment in the same school.

(3) Assessment of the psychological safety of the environment in various educational institutions had more expressed differentiation in the evaluations of the teachers than in those of the students.

(4) The psychological well-being of the students was closely correlated with the level of the psychological safety of the educational environment for teachers.

(5) Such components of the well-being of students as emotional comfort, self-confidence, a higher level of cognitive activity were developed in the schools with high levels of psychological safety for the teachers.

\section{Discussion}

Safety in the school environment for children and adolescents has been a focus of researchers and practical psychologists for quite a long time. However, scientific interest in and the need of social practice for technology that supports the safety of the school environment and its participants do not lose their relevance, despite the fact that rich experience has been gained in the sphere of prevention of situations that violate the safety of children and in relation to minimizing the impact of safety violations. 
Providing safety in the educational environment not only is an important task in the management of educational institutions but also is the condition that allows implementation of all the requirements of the society and the state in regard to the education system. One of the problematic issues in creating an effective system for providing and maintaining a safe environment in schools is the development of both a safety model for the school environment and effective technologies for assessing various parameters of a safe environment.

In analyzing research that is theoretical and that also provides a methodological basis for decisions about the development of safety in the school environment as a significant psychological characteristic, we faced a number of difficulties concerning the variety of approaches to this problem. In the development of a safety model for the educational environment, as a rule, safety is determined by the absence of disturbing situations and the absence of on-campus illegal substances, violence, injuries, and so forth. The proponents of one such model (Gastic \& Gasiewski, 2008), for example, do not take into consideration the influence of the physical environment on students' experience of safety and the safety of all participants in the school environment.

The views and opinions of Russian and foreign researchers on the content and structure of the safety of the educational environment can be divided into two main groups. The first group, whose views are within the framework of a dichotomous model, considers the physical and social settings of the educational environment; the second group proposes models that reflect a complex structure with many different elements.

One example of a successful school safety model (from the point of view of completeness and usefulness) is provided by American specialists S. Robers, J. Zhang, and J. Truman (2010). They include two indicators in a discussion of safety in the school environment: (1) objective indicators of the facts as documented by the school administration and/or local authorities; (2) indicators based on the opinions and estimates of participants in the educational environment (information about safety inhibition, action taken to provide discipline and safety in the school, personal safety at school and beyond).

Another American model (Voices from the Field, 2002) lists the following among key elements in the maintenance of safety for participants in the educational process: exit plans devised with the participation of all representatives of the relevant services; an effective system of school-based interaction and interaction with the relevant outside organizations in the event of an emergency; the opinions and participation of students in the provision of safety. Thus, American researchers pay attention to the fact that the existence of friendly relations of trust between students and administration can make a significant contribution to safety, reduce violence against participants in the educational environment, and prevent dangerous situations. Moreover, students must be active participants in the process of providing for the safety of the educational environment and be able to cooperate on safety issues with parents and administration.

The methodology and results of our research show similarity with works in which (1) safety is a term that integrates the ideas of well-being, sustainability, and equal access to resources (Hong \& Eamon, 2012) and (2) the concept of safety correlates with the results of studies of individual resilience and hardiness (Lam \& 
McBride-Chang, 2007; Maddi, 2002). We took this work into account in our studies, but at the same time, in contrast with foreign researchers and practitioners, we added both the sociopsychological factors that provide safety in the educational environment and an assessment of the level of psychological safety.

The level of the psychological safety of the educational environment is a significant condition contributing to or impeding the psychological well-being of pupils and teachers. Psychological well-being as a mental state and as a characteristic of personality is one of the most important conditions that ensure the effectiveness of the educational process. Psychological comfort and the lack of emotional and mental stress contribute to intellectual activity.

Our study showed differences between the schoolteachers and the students in their estimates of the psychological safety of the educational environment. This empirical fact can be explained by differences in their social positions: they have different degrees of responsibility for results and different age-related development, including the different features of development and professional development.

The safety of the educational environment determines its significance for students, which is expressed in the desire to belong to it. Involvement in the educational environment promotes the process of social control and the formation of socially significant values. A high level of psychological safety in the educational environment creates protection from all forms of violence, which is a necessary condition for positive intellectual and personal development. The inclusion of basic sociopsychological characteristics in the educational environment is another indicator of its psychological safety, and it promotes a capacity for work and selfconfidence.

\section{Conclusion}

Many entities provide security: from state security to safety in schools. Each element of this system is badly in need of psychological facilitation of its activities, an understanding of psychological safety features, and the ability to use them to improve efficiency. We determined that a psychologically safe educational environment is one in which most participants have a positive attitude to it, a high level of satisfaction with the characteristics of the environment, and protection against mental violence in interactions. Our study proved that there is a relationship between the psychological safety of the educational environment and the psychological well-being of its participants.

Psychological activity to provide safety precautions in education promotes transfer of the value of safety in public life, reduces the level of violence in the interactions of people, and prevents incongruent behavior and inappropriate activities of people in emergency situations. Thus safety is a resource that provides quality in the educational environment, but the role of education as a psychological resource for safety in society in general is no less important because the entire population of the country receives an education.

The important conclusion for practice is that support for a high level of psychological safety in the educational environment reduces risks and disturbance in the mental development of students. 


\section{References}

Baeva, I. A. (2002). Psyhologicheskaya bezopastnost v obrazovanii [Psychological safety in education]. St. Petersburg: Soyuz.

Baeva, I. A., Volkova, E. N., \& Laktionova, E. B. (2011). Psyhologicheskaya bezopastnost v obrazovatelnoi srede: Razvitiye lichnost $i$ [The psychological safety of the educational environment: The development of personality] (I.A. Baeva, Ed.). Moscow, St. Petersburg: Nestor-Istoriya.

Bordovskaia, N. V. (2012). Vozmozhnosti obrazovatelnoi sredyi v professionalno-lichnostnom pazvitie studentov [Opportunities in the educational environment for students' professional and personal development]. In Professionalno-lichnostnoe razvitie buduschego spetsialista [The professional and personal development of the future professional] (pp. 76-91). St. Petersburg: SPbGU.

Bordovskaia, N. V. (2013). Vyizovy vremeni i novye modeli obrazovatelnoi sredyi [The challenges of the time and new models for the educational environment]. Chelovek i obrazovanie [The individual and education], 2, 4-11.

Diener, E., \& Diener, C. (1996). Most people are happy. Psychological Science, 7, 181-185. doi: 10.1111/j.1467-9280.1996.tb00354.x

Gastic, B., \& Gasiewski, J. A. (2008). School safety under NCLB’s Unsafe School Choice Option. Perspectives on Urban Education [online], 5(2). Retrieved from http://www.urbanedjournal.org/archive/volume-5-issue-2-spring-2008/school-safety-under-nclb\%E2\%80\%99sunsafe-school-choice-option

Hong, J. S., \& Eamon, M. K. (2012). Students' perceptions of unsafe schools: An ecological systems analysis. Journal of Child and Family Studies, 21, 428-438. doi: 10.1007/s10826-0119494-8

Kulikov, L. V. (2004). Psyhogigiena lichnosti [The psychohygiene of personality]. St. Petersburg: Piter.

Lam, C., \& McBride-Chang, C. (2007). Resilience in young adulthood: The moderating influences of gender-related personality traits and coping flexibility. Sex Roles, 56(3-4), 159-172. doi: 10.1007/s11199-006-9159-Z

Leontiev, D. A. (2013). Test smyislozhiznennyich orientastyii [Life Orientation Test]. Moscow: Smysl.

Maddi, S. (2002). The story of hardiness: 20 years of theorizing, research and practice. Consulting Psychological Journal, 54, 173-185. doi: 10.1037/1061-4087.54.3.173

Maslow, A. H. (1954). Motivation and personality. New York: Harper.

Panov, V. I. (2007). Psychodidaktika obrazovatelnyich system [The psychodidactics of educational systems]. Moscow: Piter.

Robers, S., Zhang, J., \& Truman, J. (2010). Indicators of school crime and safety (NCES 2011-002/ NCJ 230812). Washington, DC: National Center for Education Statistics, U.S. Department of Education, and Bureau of Justice Statistics, Office of Justice Programs, U.S. Department of Justice.

Rubtsov, V. V. (2009). Sotsio-geneticheskya psychologiya razvivaushego obrazovaniya: Deyatelnostnyii podchod [The sociogenetic psychology of developmental education: An activity approach]. Moscow: MGPPU.

Ryff, C. D., \& Singer, B. (2008). Know thyself and become what you are: A eudaimonic approach to psychological well-being. Journal of Happiness Studies, 9(1), 13-39. doi: 10.1007/s10902006-9019-0

Shek, D. (2007). After-school time and perceived parental control processes, parent-adolescent relational qualities, and psychological well-being in Chinese adolescents in Hong Kong. Family Therapy [online], 34(2), 107-126. Retrieved from http://web.a.ebscohost.com/ehost/ 
detail/detail?sid=55650f80-3152-4106-b834-3ac8a48fab28\%40sessionmgr4001\&vid=19\&h id $=4204 \&$ bdata $=$ Jmxhbmc9cnUmc210ZT1laG9zdC1saXZl \#db=sih\&AN=27361368

Slobodchikov, V. I. (2000). O ponyatii obrazovatelnoi sredai v constepstii razvivaushego obrazovaniya [The notion of the educational environment in the concept of developmental education]. In Rossiyskaya konferentsiya po ekologicheskoy psihologii [Russian conference on ecological psychology] (pp. 172-176). Moscow: IG-SOTSIN.

Sokolova, M. V. (1996). Shcala cubektivnogo blagopoluchiya [The Scale of Subjective Well-Being]. Yaroslavl, Russia: Psihodiagnostika.

Tunik, E. E. (2002). Metodika diagnostiki lichnostnoi kreativnosti [Test of personal creativity diagnostics] In N. P. Fetiskin, V. V. Kozlov, \& G. M. Manuylov (Eds.), Sotsio-psichologicheskay diagnostika pazvitiya lichnosti i malyich grup [Sociopsychological diagnostics of personality development and small groups] (pp. 467-470). Moscow: Institut Psychoterapii.

Voices from the Field: Working Together for Safe and Secure Schools. Summary of Findings from Florida Education Commissioner Charlie Crist's School Safety and Security Summits. (2002, October). Tallahassee, FL: Florida State Department of Education and Southeastern Regional Vision for Education (SERVE) [online]. http://eric.ed.gov/?q=Summary+of+Findin gs+from+Florida+Education+Commissioner+\&id=ED471877

Volkova, E. N. (Ed.). (2011). Nasilie i shestokoe obrashenie s detmi: Istochniki, prichinyi, posledstviya, rezheniya [Violence and abuse of children: Sources, causes, effects, solutions]. St. Petersburg: Knizhnyiy Dom.

Vygotsky, L. S. (1982). Myshleniye i rech [Thinking and speech]. In Sobranie sochinenii [The collected works] (vol. 2, pp. 1-361). Moscow: Pedagogika. (Original work published 1934.)

Original manuscript received November 27, 2014

Revised manuscript accepted March 13, 2015

First published online March 31, 2015 